\title{
Vacinação Contra a COVID-19 numa Rede de Clínicas de Hemodiálise em Portugal: Uma Experiência Promissora
}

\author{
Vaccination Against COVID-19 in a Network of Hemodialysis \\ Units in Portugal: A Promising Experience
}

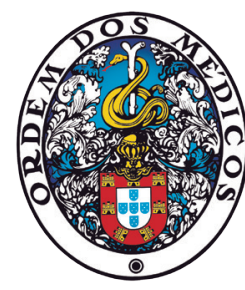

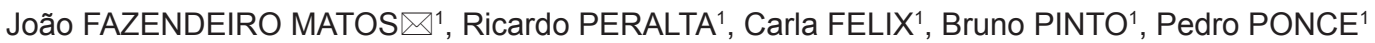 \\ Acta Med Port 2022 May;35(5):336-342 - https://doi.org/10.20344/amp.16250
}

\section{RESUMO}

Introdução: Portugal foi atingido severamente pela síndrome respiratória aguda grave (SARS-CoV-2), responsável pela doença por coronavírus 2019 (COVID-19). A população idosa e com comorbilidades, na qual estão incluídas as pessoas com doença renal crónica em estádio 5 em programa regular de hemodiálise (CKD-5D), foi particularmente afetada. Definimos como objetivos deste estudo a identificação do impacto da vacinação no surgimento de novos casos diários e a sua influência na mortalidade na população CKD-5D. Material e Métodos: Estudo observacional, prospetivo, envolvendo doentes com CKD-5D de 38 clínicas da NephroCare, Portugal. A infeção e a mortalidade diárias por SARS-CoV-2 destes doentes foi comparada com a taxa de incidência na população em geral. Foram analisados três períodos: antes da vacinação, durante, e um terceiro período após a vacinação completa pela vacina Comirnaty ${ }^{\circledR}$, da Pfizer-BioNTech. Foi considerado desfecho primário a infeção pelo vírus SARS-CoV-2 e como desfecho secundário, a morte associada à infeção.

Resultados: Foram analisados 4617 doentes com uma média de 69,37 anos. Durante o primeiro período, verificou-se uma taxa de incidência de COVID 19 de 14,9\%, significativamente maior nos doentes CKD-5D quando comparado com a taxa de incidência de 7,9\% da população em geral $(p<0,001)$. Durante os quinze dias após a vacinação completa observámos uma reversão, com diminuição significativa de casos de COVID-19 $(p<0,001)$. A mortalidade atribuível a COVID-19 no grupo CKD-5D foi significativamente superior ao da população em geral $(p<0,001)$.

Conclusão: A vacinação reduziu significativamente a infeção por SARS-CoV-2 nos doentes CKD-5D.

Palavras-chave: COVID-19; Hemodiálise; Portugal; SARS-CoV-2; Vacinas contra a COVID-19

\section{ABSTRACT}

Introduction: The severe acute respiratory syndrome coronavirus 2 (SARS-CoV-2) responsible for coronavirus disease 2019 (COVID-19) seriously affected Portugal, particularly in the elderly population with a high number of comorbidities, including patients with chronic kidney disease in stage 5 (CKD-5D) undergoing a regular dialysis program. The aims of this study were to identify the impact of vaccination on the incidence of new daily cases and mortality in the CKD-5D population.

Material and Methods: Prospective, observational study, involving patients with CKD-5D from 38 NephroCare clinics, Portugal. Daily SARS-CoV-2 infections and mortality among these patients was compared with the incidence in the general population. Three periods were analysed: before vaccination, during the vaccination process, and a third period after complete vaccination with the PfizerBioNTech' Comirnaty ${ }^{\circledR}$ vaccine. The primary outcome was infection by the SARS-CoV-2 virus and the secondary outcome was death associated with the infection.

Results: A total of 4617 patients (average of 69.37 years of age) were analysed. During the first period, there was a significantly higher COVID-19 incidence of $14.9 \%$ in patients with CKD-5D compared with the general population $(7.9 \% ; p<0.001)$. During the fifteen days after the complete vaccination, results reverted to a significant decrease in COVID-19 cases was observed $(p<0.001)$. The mortality rate among CKD-5D was significantly higher than in the general population $(p<0.001)$.

Conclusion: Vaccination significantly reduced SARS-CoV-2 infection in patients with CKD-5D.

Keywords: COVID-19; COVID-19 Vaccines; Hemodialysis; Portugal; SARS-CoV-2

\section{INTRODUÇÃO}

Desde o final do ano de 2019, o vírus SARS-CoV-2 (severe acute respiratory syndrome coronavirus 2), responsável pela doença por coronavírus de 2019 (COVID-19), já causou mais de 231409495 infeções e 4741732 mortes no mundo inteiro, de acordo com os dados disponibilizados a 25 set de 2021, pela John Hopkins University (Estados Unidos da América). ${ }^{1}$ Apesar do primeiro caso deste novo coronavírus ter sido identificado na cidade de Wuhan, na província de Hubei, China Continental, rapidamente se propagou a diversas regiões, incluindo Portugal.

O conceito de 'sindemia', ${ }^{2}$ descrito pela primeira vez por Merril Singer nos anos 90, ganhou ainda mais relevância durante esta pandemia, [declarada a 11/03/2020 pela Or- ganização Mundial de Saúde (OMS)], pela influência das iniquidades no curso das doenças e sobretudo nos desfechos, particularmente sobre as desigualdades sociais, os aspetos económicos, os grupos etários, as condições de saúde prévias e o acesso aos cuidados de saúde. ${ }^{3}$

Em Portugal, entre 02/03/2020 - data da identificação do primeiro caso de COVID-19 - e 16/03/2021, a doença afetou 814513 pessoas, registando-se a essa data 36031 casos ativos e 16694 mortos, sobretudo na população com idade mais avançada e com doença prévia. A terceira vaga, que se fez sentir em Portugal após o período de Natal, foi particularmente dura, provocando uma elevada pressão sobre os sistemas de saúde em geral, o que originou a

\footnotetext{
1. NephroCare Portugal. Fresenius Medical Care Portugal. Porto. Portugal.

$\triangle$ Autor correspondente: João Fazendeiro Matos. jfazendeiro.matos@fmc-ag.com

Recebido/Received: 23/03/2021 - Aceite/Accepted: 09/09/2021 - Publicado Online/Published Online: 05/11/2021 - Publicado/Published: 02/05/2022 Copyright $\odot$ Ordem dos Médicos 2022
} 
sobrelotação de camas em enfermarias e mesmo em unidades de Cuidados Intensivos (UCI). Apesar das medidas implementadas e/ou reforçadas antecipadamente pelos centros de hemodiálise (CHD) - nomeadamente organizacionais, controlando fluxos de pessoas e trabalho, especialmente os processos de higiene e controlo de infeção - as pessoas com doença renal crónica em estádio 5 (CKD-5D), em programa regular de substituição da função renal por hemodiálise em centro, foram fortemente atingidas ao longo da pandemia por SARS-CoV-2 e de modo particularmente severo no decorrer da terceira vaga.

Trata-se de um segmento da população com elevada vulnerabilidade, ${ }^{4}$ não passível de confinamento restrito, devido à necessidade de receber tratamento regular pelo menos três vezes por semana. Existe, por isso, a necessidade de deslocação em transporte maioritariamente partilhado o que, apesar do esforço realizado pelas autoridades de saúde e por todos os operadores envolvidos em garantir as condições de segurança ideais, representa um risco acrescido. Adicionalmente, não obstante o uso de equipamentos de proteção individual e de medidas de higiene e distanciamento, os doentes são expostos a múltiplos contactos, especificamente no processo de realização do tratamento, necessariamente a menos de um metro dos cuidadores.

A resposta imunitária dos doentes renais crónicos às vacinas disponíveis, e qual a dose específica que possa ser eficaz para este grupo de doentes, é desconhecida. Porém, assistimos por parte das autoridades de Saúde portuguesas, à inclusão na primeira fase de prioridades para a vacinação contra a COVID-19 da população hemodialisada e dos profissionais dos CHD. Tratou-se de um enorme empreendimento logístico e operacional, que decorreu em estreita colaboração com a task-force para a vacinação do Ministério da Saúde, para quem os CHD funcionaram como postos avançados de vacinação. A vacina utilizada neste grupo prioritário foi a Comirnaty ${ }^{\circledR}$, da Pfizer-BioNTech.

O universo das clínicas de hemodiálise em Portugal, é potencialmente um grupo com uma elevada taxa de proteção, quer por via da vacinação, quer por infeção prévia de doentes e profissionais. Deste modo, definimos como objetivos deste estudo, a identificação do impacto da vacinação no surgimento de novos casos diários e a sua influência na mortalidade na população CKD-5D.

\section{MATERIAL E MÉTODOS \\ Desenho do estudo}

Estudo epidemiológico, prospetivo, observacional, envolvendo todos os doentes com CKD-5D em programa regular de hemodiálise em 38 clínicas de hemodiálise da NephroCare em Portugal, (Fresenius Medical Care - Portugal).

\section{Participantes}

Para tentar compreender a influência da vacinação em massa num curto espaço de tempo de uma coorte bem definida de doentes, com follow-up assegurado a 100\% no surgimento de novos casos no ecossistema da diálise em Portugal, comparámos a variação da taxa de incidência diária da população hemodialisada (4617 doentes), com a variação da taxa de incidência diária da população em geral, para identificar pontos de divergência nos períodos pré e pós vacinação (Fig. 1).

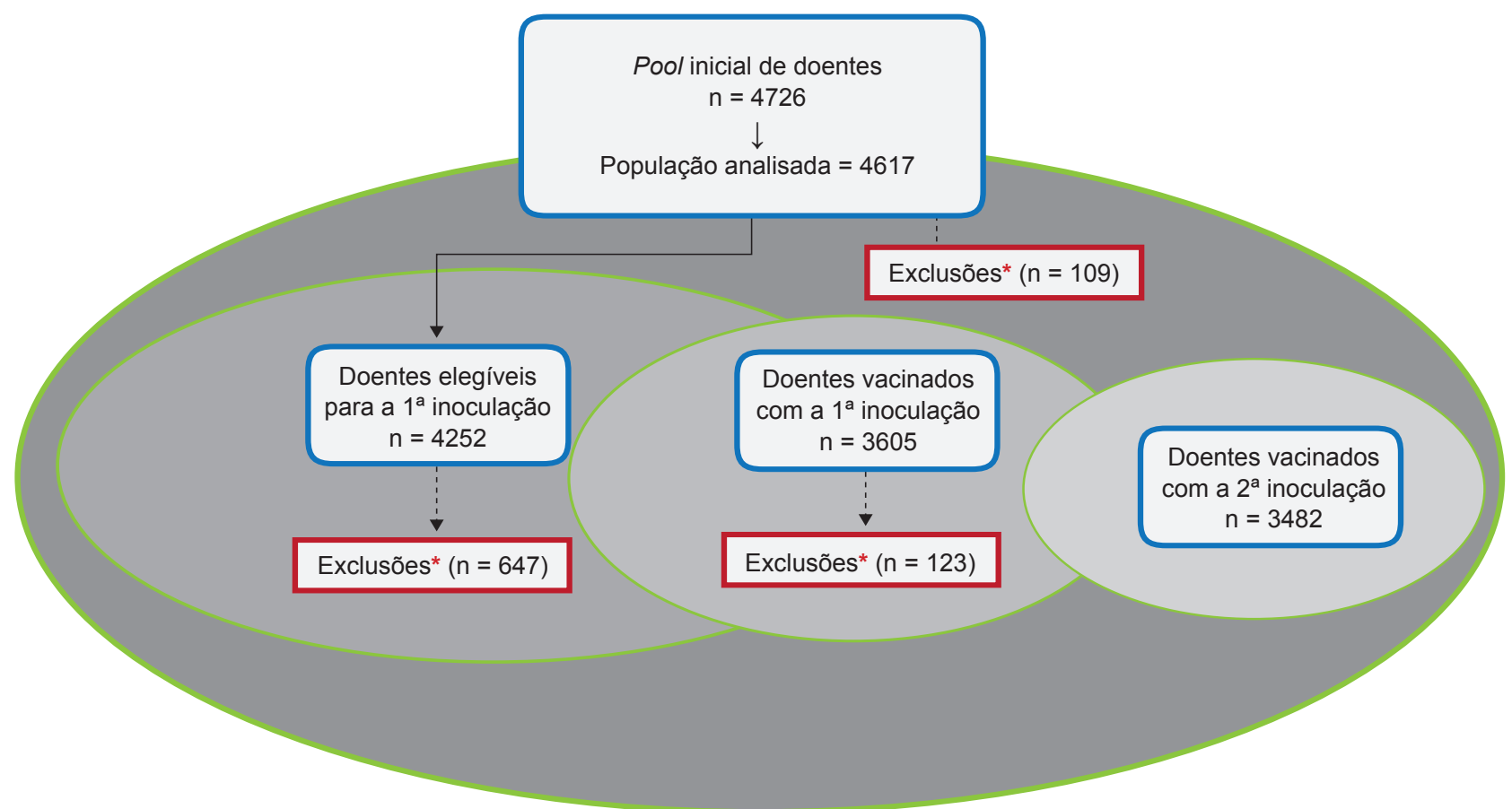

Figura 1 - Desenho do estudo. De uma pool inicial de 4726 doentes, por exclusão de 109 doentes (* - por morte, internamento, recusa do doente, contra indicação clínica, infeção prévia a SARS CoV-2), foram analisados 4617 doentes. Destes, foram elegíveis 4252 doentes para primeira inoculação, tendo sido primo inoculados 3605 por exclusão de 647 doentes*. Efetuaram a segunda inoculação 3482 doentes, por exclusão de $123^{*}$. 
Como critérios de exclusão da vacinação, foram considerados todos os doentes que tiveram previamente $\mathrm{CO}$ VID-19, recusa ou doentes hospitalizados no período de administração da mesma. Todos os restantes foram considerados elegíveis de acordo com as normas da Direção Geral de saúde (DGS) n021/2020 de 23/12/2020 atualizada a $01 / 03 / 2021^{5}$ e no002/2021 de 30/01/2021 atualizada a $10 / 03 / 2021{ }^{6}$

\section{Procedimentos}

As clínicas de hemodiálise tomaram medidas de proteção relativamente aos seus doentes e colaboradores, no sentido de minimizar a incidência e impactos associados à infeção por SARS-CoV-2, nas quais se inclui a agilização da comunicação, utilização de EPI adequado, formação e implementação das normas e orientações da DGS. Os doentes hemodialisados foram incluídos na primeira fase de vacinação por parte da task-force do Ministério da Saúde, dando cumprimento à norma da DGS n 002/2021 de 30/01/2021 atualizada a 10/03/2021. ${ }^{7}$ A vacinação da população hemodialisada decorreu entre os dias 27 e 30 de janeiro para a primeira dose e entre os dias 17 e 20 de fevereiro para a segunda dose.

A análise pré vacinação teve como intervalo temporal o período compreendido entre a identificação do primeiro caso em Portugal (02/03/2020) e o $15^{\circ}$ dia (13/02/2021) após a primeira inoculação aos doentes. A análise de variação pós vacinação foi realizada em dois intervalos distintos, sendo o primeiro entre o $16^{\circ}$ dia (14/02/2021) após a primeira inoculação e o sétimo dia (27/02/2021) após a segunda inoculação, e um segundo com início no oitavo dia (28/02/2021) após a segunda inoculação até 15/03/2021 (follow-up de 15 dias, o que inclui sete dias após o que se considera a vacinação completa). ${ }^{8}$

Dada a elevada flutuação nas notificações de novos casos diários relacionada com o dia da semana, em que se observa uma importante redução nos dias de sábado e domingo, sentimos necessidade de encontrar uma forma de normalizar os dados, pelo que recorremos ao cálculo do número médio diário de casos referente aos últimos sete dias. Por se tratar de amostras com grandezas muito diversas, isto é, a população do país [aproximadamente 10 295909 habitantes de acordo com o censos Portugal 2021, Instituto Nacional de Estatística (INE)] ${ }^{9}$ e a população hemodialisada nas clínicas da NephroCare Portugal (4617 doentes), os cálculos da taxa de incidência de novos casos foram relativizados a 100000 pessoas. Como desfecho primário foi considerada a infeção por vírus SARS-CoV-2, confirmada pela técnica laboratorial RT-PCR (transcrição reversa seguida de reação em cadeia da polimerase).

Os doentes foram sujeitos à realização de testes RT-PCR de acordo com os critérios definidos na Norma da DGS n ${ }^{\circ}$ 019/2020 de 26/10/2020 atualizada a 26/02/2021, ${ }^{10}$ isto é, em função da sintomatologia e suspeita de infeção por SARS-CoV-2, e na identificação e diagnóstico de contactos de alto e baixo risco.

Como desfecho secundário, foi considerada a morte do doente com CKD-5D, associada à infeção por SARS-CoV-2.

Para avaliar o impacto da infeção por SARS-CoV-2 na mortalidade da população hemodialisada, foram avaliadas a mortalidade por COVID-19 em relação ao total de doentes e a medida da taxa de letalidade (\%) associada à doença (COVID-19) para os casos que já têm um desfecho - outcome, isto é, que foram considerados curados ou que resultaram na morte do doente [mortes/(casos recuperados + mortes) $x$ 100] designada por case fatality rate após outcome (CFR-O), e comparados os resultados com a população em geral.

\section{Tratamento estatístico}

A análise de dados foi conduzida em ambiente SPSS, versão 23 (IBM, Armonk, NY, EUA). Na descrição das variáveis categóricas foram utilizadas frequências absolutas (n) e relativas (\%). No caso das variáveis contínuas com distribuição simétrica foram utilizadas médias (M) e desvios padrão (DP); caso contrário foram utilizadas medianas e amplitudes inter-quartil. A simetria foi avaliada pelo coeficiente de assimetria (simetria quando [-2; 2]) e complementada com a observação do histograma. A normalidade das distribuições foi avaliada pelo teste Kolmogorov-Smirnov. $O$ teste de Mann-Whitney $U$ foi utilizado para testar as diferenças entre a taxa de incidência de infeção nos doentes com CKD-5D e a da população em geral nos 3 períodos. Para todas as comparações, foi estabelecido o nível de significância de $p<0,05$.

\section{Ética}

Este estudo foi aprovado pela Comissão de Ética da Fresenius Medical Care, Portugal, de acordo com a declaração de Helsínquia. Foi dispensado pela mesma comissão a necessidade de consentimento informado, uma vez que os dados foram extraídos centralmente, anonimizados e sem possibilidade de reversão, de forma cega para os investigadores.

\section{RESULTADOS}

Neste estudo foram analisados dados de 4617 doentes, dos quais 2765 (59,9\%) são do género masculino. A idade da população hemodialisada na NephroCare Portugal variou entre os 19 e os 97 anos, com uma média de 69,37 (DP = 14,08) anos, (IQR, 61 - 80) (Tabela 1). Apresentaram múltiplas comorbilidades para além da CKD-5D, nomeadamente $35,3 \%$ de doentes eram diabéticos com um índice de Charlson médio de 4,11 (DP = 2,02).

Do total de doentes, $621(13,45 \%)$ frequentavam instituições de apoio à terceira idade, estando $345(7,47 \%)$ em regime residencial, sendo conhecido que estes tipos de estruturas de apoio foram também severamente atingidos pela COVID-19, o que se traduz num fator de risco acrescido. Neste contexto, verificámos nos doentes hemodialisados uma taxa de incidência de $14,92 \%$ de COVID-19, com uma taxa de recuperação de $81,57 \%$, uma taxa de mortalidade por COVID-19 de 2,38\% e um CFR-O de 16,37\%. 
Tabela 1 - Caraterísticas demográficas da população em estudo

\begin{tabular}{lc}
\hline Variáveis & $\begin{array}{c}\text { Total } \\
(\mathrm{n}=4617)\end{array}$ \\
\hline Demográficas & \\
Género masculino, $\mathrm{n}(\%)$ & $2765(59,9 \%)$ \\
Idade (anos), média (DP) & $69,37(14,08)$ \\
Índice de Comorbilidade de Charlson, média (DP) & $4,11(2,02)$ \\
Tempo em diálise (meses), média (DP) & $78,42(79,10)$ \\
Diabetes, $n(\%)$ & $1632(35,3 \%)$ \\
Institucionalizados/residentes em lar & $621(13,45 \%)$ \\
Tipo de Acesso Vascular, $n$ (\%) & \\
Fístula arteriovenosa & $3203(69,4 \%)$ \\
Enxerto arteriovenoso & $467(10,1 \%)$ \\
Cateter venoso central & $947(20,5 \%)$ \\
\hline
\end{tabular}

Na população em geral (dados de 16 de março de 2021), a taxa de incidência foi de $7,94 \%$, a taxa de recuperação de $93,53 \%$, a mortalidade de $0,16 \%$ e o CFR-O foi de $2,14 \% .{ }^{11}$

Quando comparados os novos casos por 100000 habitantes com a população hemodialisada nas clínicas do grupo NephroCare Portugal (Fig. 2), no período compreendido entre o primeiro caso notificado em Portugal e o $15^{\circ}$ dia após a primeira inoculação da vacina aos doentes hemodialisados, apesar de se verificarem algumas flutuações, observa-se uma taxa de incidência da doença por 100000 pessoas significativamente superior $(p<0,001)$ na população hemodialisada, com picos da taxa de incidência até cinco vezes superior ao da população em geral. Neste período, a taxa de incidência média diária foi de 41,39/100 000 pessoas na população hemodialisada e 22,42/100 000 na população em geral.
Efetuando a mesma comparação para o período com início no $16^{\circ}$ dia após a primeira inoculação e o sétimo dia após a segunda inoculação, observa-se uma taxa de incidência média diária de 13,68/100 000 pessoas na população hemodialisada e 14,09/100 000 na população em geral, não tendo sido observado significado estatístico ( $p=$ 0,541).

A tendência de dissociação das curvas da taxa de incidência, que se observou a partir do $16^{\circ}$ dia após a primeira inoculação, viria a acentuar-se ao oitavo dia após a segunda inoculação (vacinação completa). A taxa de incidência média diária dos últimos sete dias na população hemodialisada, a partir do sétimo dia após a segunda dose (vacinação completa), foi de 1,33/100 000, enquanto para a população em geral foi de 6,65/100 000 habitantes. Neste período, observou-se uma redução significativa da taxa de incidência na população CKD-5D, quando comparada com a população em geral $(p<0,001)$ (Fig. 3)

Quanto à mortalidade e CFR-O para a população hemodialisada e população em geral, observamos uma importante assimetria, com a população hemodialisada a ser particularmente atingida. Observámos ainda que a mortalidade devida à COVID-19 foi de 2,38\% nos CKD-5D em comparação com $0,16 \%$ na população em geral $(p<0,001)$ e o CFR-O de $16,37 \%$ versus $2,14 \%$, respetivamente. Observámos também que a média do tempo desde a identificação da infeção até à morte na população com CKD-5D foi de 13,29 DP = 10,92 dias (IQR 6 - 17) com um mínimo de 1 e um máximo de 52 dias.

\section{DISCUSSÃO}

As pessoas com CKD-5D apresentaram uma elevada taxa de incidência à infeção por SARS-CoV-2, agravada

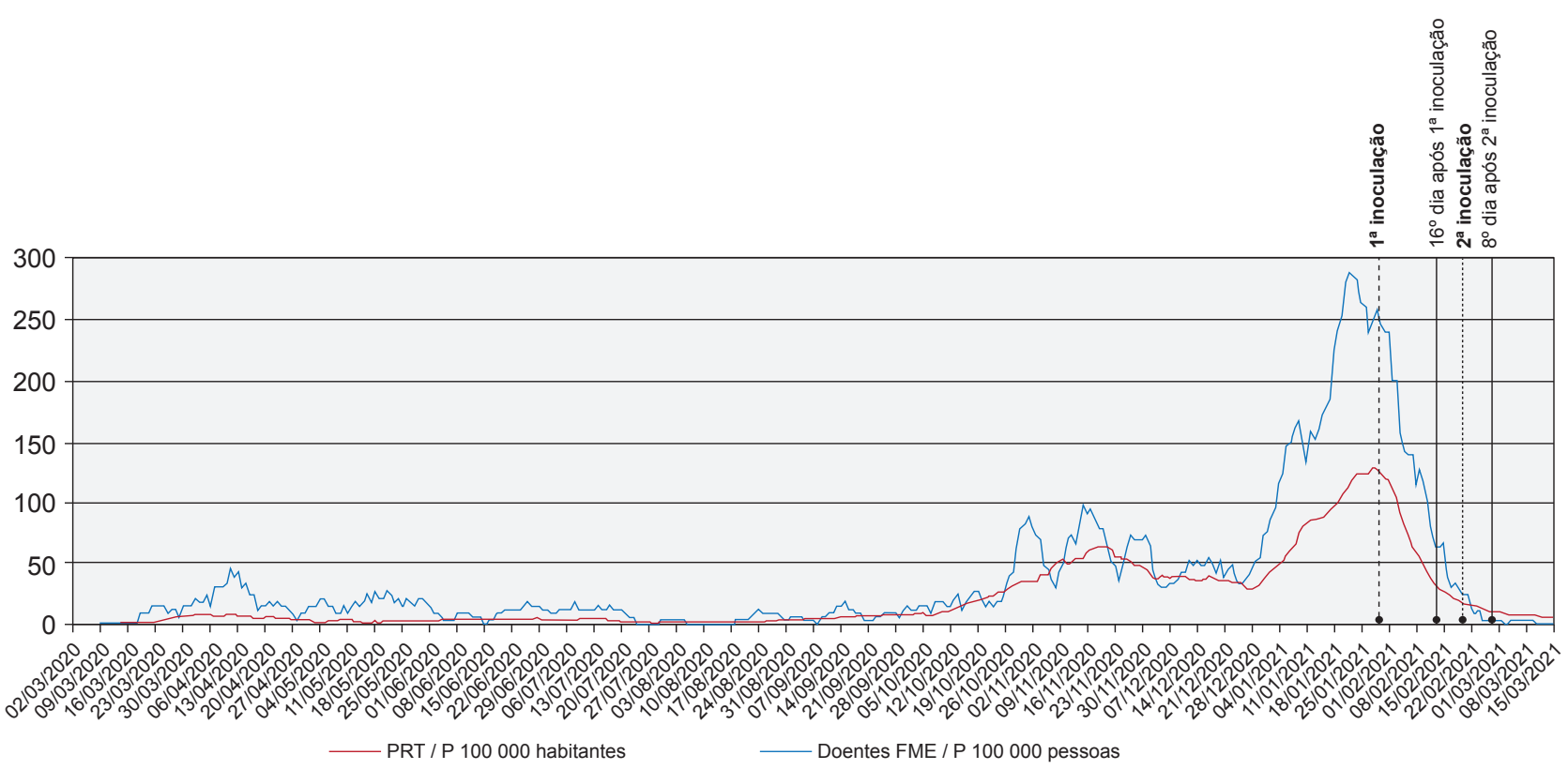

Figura 2 - Representação gráfica da média diária a sete dias da taxa de incidência ao longo do período em análise, para os dois grupos em estudo.

PRT: Portugal; FME Pts: doentes em seguimento na Fresenius Medical Care 
Média de incidência diária por 100000 pessoas

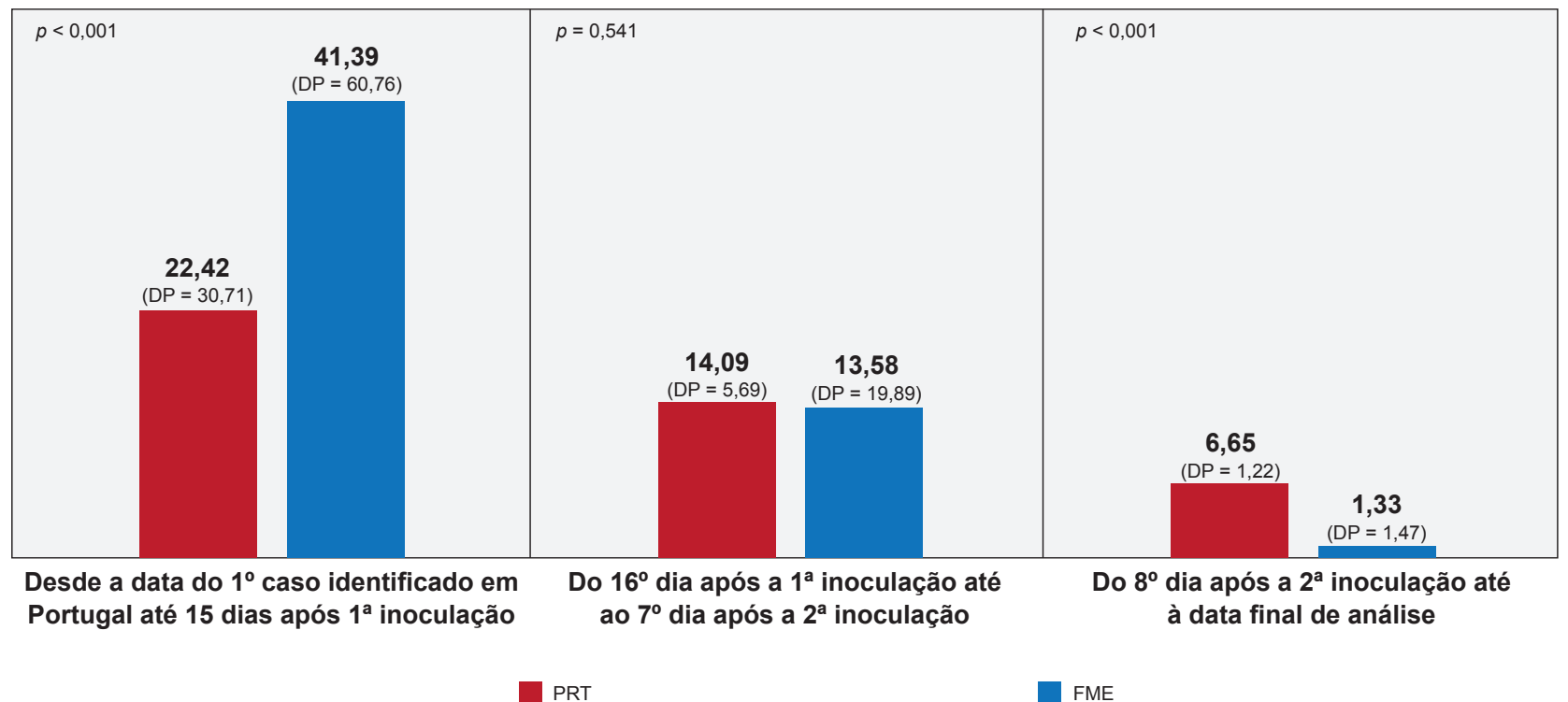

Figura 3 - Representação gráfica da média diária de taxa de incidência da infeção pelo vírus SARS-CoV-2 por 100000 pessoas. O primeiro período decorreu desde a data do primeiro caso identificado em Portugal até ao $15^{\circ}$ dia após a primeira inoculação da vacina Comirnaty ${ }^{\circledR}$ da Pfizer-BioNTech. O segundo período decorreu desde o $16^{\mathrm{a}}$ dia da primeira inoculação até ao sétimo dia após a segunda inoculação (vacinação completa). O terceiro período decorreu desde o oitavo dia após a vacinação completa até ao dia 15/03/2021 (fecho do estudo).

PRT: Portugal; FME Pts: doentes em seguimento na Fresenius Medical Care

não apenas pela idade, ${ }^{12,13}$ múltiplas comorbilidades ${ }^{4} \mathrm{e}$ diabetes, ${ }^{14,15}$ mas também pelas condições sociodemográficas. O facto de $13,45 \%$ dos doentes residirem ou frequentarem instituições de apoio, representou um fator de risco significativo de acordo com o estudo de Caroline M. Hsu. ${ }^{14}$ A elevada exposição institucional da população hemodialisada em estudo e a combinação dos restantes fatores condicionam, inevitavelmente, as elevadas taxas de mortalidade e letalidade em comparação com a população em geral. ${ }^{14}$

De acordo com os resultados obtidos na comparação da população hemodialisada nas clínicas do grupo $\mathrm{Ne}$ phroCare Portugal com a população em geral observámos, sobretudo na terceira vaga, uma taxa de incidência muito superior nos doentes hemodialisados, apesar de potenciais viés relacionados com as diferentes estratégias de testagens nos diversos grupos populacionais, mesmo considerando a elevada testagem realizada em Portugal. Contudo, verificou-se uma redução de incidência média após a administração da primeira dose da vacina contra a COVID-19, tendência esta que aumentou após a administração da segunda dose. No período de 15 dias, com início no oitavo dia após a administração da segunda dose da vacina, a taxa de incidência média no grupo de hemodialise foi já inferior ao da população em geral.

Estes resultados sugerem que este grupo de doentes, pela sua vulnerabilidade, requer por um lado uma atenção e cuidados acrescidos e suporte substancial durante a fase de pandemia, e por outro beneficia de uma importante vantagem associada à vacinação atempada e em massa. Apesar de não existirem neste momento publicações acerca desta temática, consideramos serem necessários mais estudos que confirmem esta observação, nomeadamente a percentagem de seroconversão e sustentabilidade da resposta imunitária ao longo do tempo. A vacinação contra a COVID-19 na população hemodialisada revelou ser uma medida extremamente promissora, com uma importante redução do número de novas infeções identificadas, sendo previsível uma redução de morbilidade e mortalidade associada a este grupo específico de doentes. Acreditamos que esta nossa experiência poderá ser extrapolada para a população em geral, sugerindo o benefício acrescido de vacinação massificada de grandes grupos de indivíduos na maximização da redução de novos casos e no controle da transmissão em comunidades confinadas.

A oportunidade de proceder a esta campanha de vacinação coincidiu no seu início com o pico de incidência de novos casos da doença na nossa rede de clínicas e simultaneamente na comunidade onde se inserem. Ao longo do período de observação entre doses de vacinação e pós-vacinação, assistiu-se a uma redução da incidência de COVID-19 na comunidade, provavelmente associada à declaração do estado de emergência e consequentes medidas de confinamento, o que poderá confundir a leitura dos benefícios efetivos da vacina. Importa por isso distinguir estes dois efeitos concomitantes.

Como desfecho secundário, consideramos o CFR obtido no grupo com CKD-5D bastante inferior aos $23,8 \%$ observados no estudo de Mabel Aoun ${ }^{4}$ e aos $25 \%$ do estudo ERACODA ${ }^{12}$ conduzido em vários países da Europa.

No que diz respeito à média do tempo desde o diagnóstico até à morte, no grupo estudado foi de 13,29 dias. Os resultados dos diversos estudos são heterogéneos variando de uma média de seis dias no estudo Libanês ${ }^{4}$ até uma 
média de 18,5 dias no estudo de Fei Zhou et al. ${ }^{16}$ Serão necessários estudos posteriores para avaliar a influência da vacinação na redução da mortalidade.

Como limitação, consideramos existir um enviesamento nos dados uma vez que os participantes no grupo estudado (doentes hemodialisados) integram também o outro grupo (população em geral) ainda que apenas de forma residual $(<0,05)$. De referir também que os doentes com história prévia de infeção por SARS-CoV-2, e os doentes com contraindicação ou que recusaram a vacinação, foram também incluídos na análise de incidência após vacinação completa.

Apesar das limitações identificadas, existem múltiplos aspetos que tornam este estudo único nomeadamente os resultados serem provenientes de uma base de dados robusta e com adesão total garantida - EuCliD-5 - e a dimensão da amostra.

\section{CONCLUSÃO}

Na nossa rede de clínicas conseguimos, com uma operação de vacinação em massa de praticamente toda a população em risco, obter um grau de imunidade significativo num curto espaço de tempo, o que é difícil de reproduzir na comunidade em período semelhante. Esta experiência piloto, ainda que numa população cuja resposta imunitária à vacinação possa estar comprometida, servirá de modelo para os benefícios expectáveis a curto e médio prazo para uma política de vacinação tendencialmente universal organizada em subgrupos. De acordo com os dados observados, a vacinação contribuiu para a redução do surgimento de novos casos entre os CKD-5D.

Quanto à mortalidade associada, é de esperar uma redução significativa do número de mortes por COVID-19, devido à redução de novos casos, resultante da imunidade do subgrupo.

A reprodutibilidade desta metodologia poderá contribuir para a implementação de futuras campanhas de vacinação em subgrupos específicos da população.

\section{AGRADECIMENTOS}

Pelo profissionalismo e resiliência demonstrada ao longo do último ano, e que foi determinante para a minimização dos impactos da pandemia nos doentes em diálise, os autores manifestam publicamente o seu agradecimento a todos os profissionais das clínicas de hemodiálise do grupo, os verdadeiros executantes no terreno do plano de vacinação.

Os autores gostariam de agradecer a revisão crítica do manuscrito pela infeciologista Dra. Diana Seixas.

\section{CONTRIBUTO DOS AUTORES}

JFM: Desenho do estudo, análise e interpretação dos dados, redação do manuscrito, revisão e aprovação da versão final.

RP: Desenho do estudo, análise e interpretação dos dados, redação do manuscrito.

CF, BP: Análise e interpretação dos dados, redação do manuscrito.

PP: Análise e interpretação dos dados, redação do manuscrito, revisão e aprovação da versão final.

\section{PROTEÇÃO DE PESSOAS E ANIMAIS}

Os autores declaram que os procedimentos seguidos estavam de acordo com os regulamentos estabelecidos pelos responsáveis da Comissão de Investigação Clínica e Ética e de acordo com a Declaração de Helsínquia da Associação Médica Mundial atualizada em 2013.

\section{CONFIDENCIALIDADE DOS DADOS}

Os autores declaram ter seguido os protocolos do seu centro de trabalho acerca da publicação de dados.

\section{CONFLITOS DE INTERESSE}

Todos os autores pertencem aos quadros da NephroCare Portugal.

\section{FONTES DE FINANCIAMENTO}

Este trabalho não recebeu qualquer tipo de suporte financeiro de nenhuma entidade no domínio público ou privado.

8. Centers for Disease Control and Prevention. When you have been fully vaccinated. 2021. [consultado 2021 março 16]. Disponível em: https:// www.cdc.gov/coronavirus/2019-ncov/vaccines/fully-vaccinated.html.

9. Instituto Nacional de Estatistica. População residente. 2021 [consultado 2021 março 15). Disponível em: https://www.ine.pt/xportal/ xmain?xpid=INE\&xpgid=ine_main.

10. Direção Geral de Saúde. Norma n $019 / 2020$ de 26 de outubro de 2020 atualizada a 26 de fevereiro de 2021. Estratégia nacional de testes para SARS-CoV-2. Lisboa: DGS; 2021.

11. Direção Geral de Saúde. Covid-19 | relatório de situação n 378 | 15-032021. 2021. [consultado 2021 mar 16). Disponível em: https://covid19. min-saude.pt/relatorio-de-situacao/.

12. Hilbrands LB, Duivenvoorden R, Vart P, Franssen $C$, Hemmelder $M$ Jager $\mathrm{K}$, et al. COVID-19-related mortality in kidney transplant and dialysis patients: results of the ERACODA collaboration. Nephrol Dial Transplant. 2020;35:1973-83.

13. Jager KJ, Kramer A, Chesnaye NC, Couchoud C, Sánchez-Álvarez JE, Garneata L, et al. Results from the ERA-EDTA Registry indicate a high 
mortality due to COVID-19 in dialysis patients and kidney transplant recipients across Europe. Kidney Int. 2020;98:1540-8.

14. Hsu CM, Weiner DE, Aweh G, Miskulin DC, Manley HJ, Stewart, et al. COVID-19 infection among US dialysis patients: risk factors and outcomes from a national dialysis provider. Am J Kidney Dis. 2021;77:748-56.e1.

15. Richardson S, Hirsch JS, Narasimhan M, Crawford JM, McGinn T,
Davidson KW, et al. Presenting characteristics, comorbidities, and outcomes among 5700 patients hospitalized with COVID-19 in the New York city area. JAMA. 2020;323:2052-9.

16. Zhou F, Yu T, Du R, Fan G, Liu Y, Liu Z, et al. Clinical course and risk factors for mortality of adult inpatients with COVID-19 in Wuhan, China: a retrospective cohort study. Lancet. 2020;395:1054-62. 